\title{
Imprinting as an independent variable in the modeling of a low-probability behavior in chicks
}

\author{
NORMA C. REESE \\ University of Southern Mississippi, Hattiesburg, Mississippi 39401
}

\begin{abstract}
The purpose of the present study was to examine observational learning in chicks as a function of the use of an imprinted vs. a nonimprinted model. Chicks imprinted on other chicks and chicks imprinted on a red tennis ball were exposed to one of three conditions. These were: (1) observing the imprinted model solve an umweg problem, (2) observing the nonimprinted model solve an umweg problem, and (3) attempting to solve the umweg problem with no exposure to a model. Chicks exposed to a model solved the umweg problem significantly faster than control chicks. Furthermore, chicks imprinted on red tennis balls were faster in solving the problem than chicks imprinted on other chicks.
\end{abstract}

Observational learning in chicks should be effective since chicks are social animals and have excellent visual acuity (Resevez, 1934). Furthermore, imprinting studies (Bateson \& Reese, 1968) suggest that imprinting stimuli are powerful commanders of the chicks' attention. This would suggest that imprinting should enhance the stimulus value of a model when the model and the imprinting stimulus are identical. It would also be expected that the percentage of time spent by a chick observing a model on which it had been imprinted would be greater, allowing more time for observation to occur.

It was the purpose of the study to explore the effects of differential imprinting and exposure to imprinted modeling stimuli on the delayed reproduction of a novel response.

The following hypotheses were tested: (1) Chicks raised with an inanimate object on which they had been imprinted should demonstrate the same activity levels as chicks imprinted on other chicks in a standard brooder. (2) Response latencies in solving a novel problem (the umweg problem) should be shorter for chicks exposed to either an imprinted or a nonimprinted model than for chicks not exposed to a model. (3) In solving a novel problem (the umweg problem), chicks exposed to an imprinted model should demonstrate shorter latencies than chicks exposed to a nonimprinted model.

\section{METHOD}

\section{Subjects}

The subjects were 72 8-day-old Cob \& Cob chicks placed alternately into Group A or Group B as they hatched in the laboratory. Chicks were watered and maintained on 2 oz per day Chick Startena in a white 5-oz cup. Temperature was maintained at $84^{\circ} \mathrm{F}$ and cages were brigh tly lit from 7 a.m. to 7 p.m.

This experiment is based on a portion of a thesis submitted by Norma $C$. Reese in partial fulfillment of the requirements of master's degree at the University of Southern Mississippi and presented at the March 27-29, 1975 meeting of the Southern Society for Philosophy and Psychology in New Orleans. Request reprints from Norma C. Reese, Box 1174 Southern Station, University of Southern Mississippi, Hattiesburg, Mississippi 39401. J. C. Koeppel sponsors and takes full responsibility for this paper.

\section{Apparatus}

Imprinting apparatus consisted of a 6-ft-diam runway with a 15-in.-wide track. A motor attached to a rotating arm carried a suspended red tennis ball around the track with speed controlled by a variable rheostat.

The umweg problem was employed as it has been demonstrated to be a low-probability response in chicks (Thorndike, 1898; Munn, 1957) in which the chick, placed behind a three-sided barrier, must learn to go away from a desired object (food on the other side) in order to obtain it. The umweg was a 4 -in.-high three-sided hardware cloth barrier on a 4 in. $x 4$ in. solid base lined with an $81 / 2$-in.-high sheet of clear plastic to prevent chicks from climbing over the barrier.

The umweg was centered in a 10 in. $\times 12$ in. x 11 in. Ralph Gerbrands Company conditioning box lined with black paper for visual isolation. Food was placed in a $5-\mathrm{oz}$ white plastic cup in front of the barrier. Three observation cells were attached to each side of the box. These were 3-3/4 in. deep, painted black with a 3 in. $x 6$ in. window facing the umweg.

\section{Design}

The experimental design consisted of two imprinting groups and three conditions of observation. Group A subjects were automatically imprinted on other chicks and raised in a standard brooder. Group B chicks were imprinted on red tennis balls using standard imprinting procedures (Hess, 1958). Group B chicks were then housed individually with a red tennis ball suspended from the cage roof since this procedure has been demonstrated to reduce the death rate in pilot studies. In Condition I, 12 Group A and 12 Group B chicks observed a chick trained to run around a three-sided barrier to obtain food. In Condition II, 12 Group A and 12 Group B chicks observed a red tennis ball manipulated by the experimenter perform with the same latencies. Condition III was a control condition in which 12 subjects from Group A and 12 subjects from Group B were not exposed to a model.

\section{Procedures}

Five chicks from Group B were trained as models. They were shaped on the 4 th through 7 th days by following the red tennis ball around the barrier to the food until they could perform alone.

On the 7th day, chicks in Group A and Group B were alternately tested for $60 \mathrm{sec}$ on a $3 \mathrm{ft} \times 5 \mathrm{ft}$ field of 4 in. $\times 4$ in. tiles, and the number of tiles entered was recorded as an index of activity level.

On the 8th day, chicks were numbered and randomly assigned 12 to each condition. Two experimenters were present to manipulate the apparatus and record scores. 


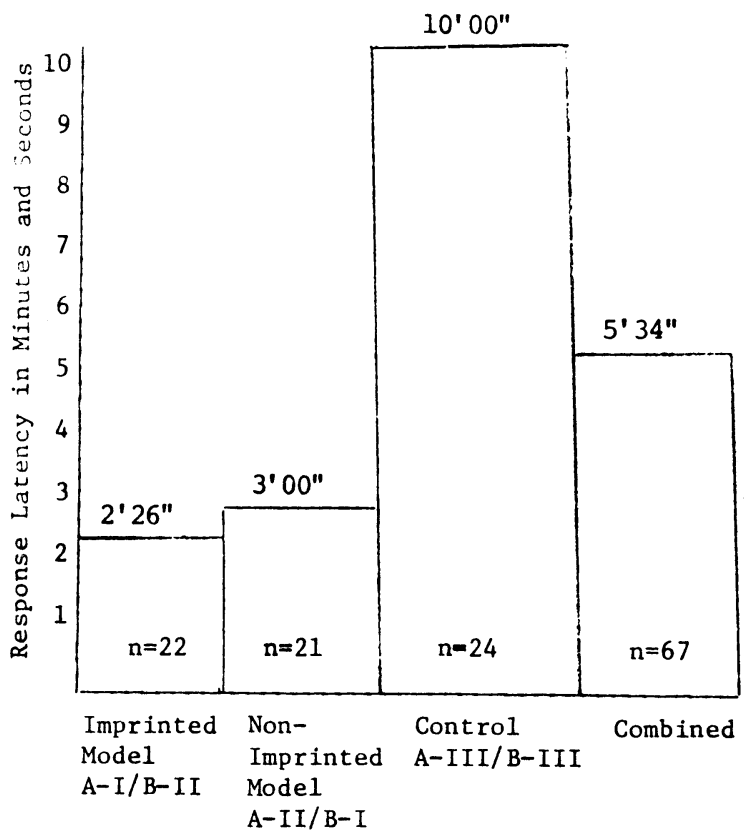
test.

Figure 1. Median response latencies demonstrated on umweg

Six subjects were run in each session (three Group A and three Group B). In half of the sessions, Group A observed from the right and in half from the left. Observers were exposed to a model which was placed into the umweg 10 times and allowed to run around the barrier to eat for $5 \mathrm{sec}$. After each session, Group A and Group B subjects were alternately placed in the problem box alone for $10 \mathrm{~min}$ or until they went around the umweg for food.

A Condition I session with a live model was followed by a Condition II session in which the latencies of the live model were matched by experimenter manipulations of the red tennis ball. A Condition II session followed in which three chicks from each group were alternately tested without modeling exposure. In the first and third session of each condition, chicks were tested $A B A B A B$. In the second and fourth sessions of each condition, chicks were tested BABABA.

Scores were recorded as number of seconds between placement of the chicks into the umweg and the first peck at the food. All sessions were completed between 6 a.m. and 4 p.m.

\section{RESULTS}

Data were analyzed with the extension of the median test (Siegel, 1956). Two subjects were dropped from Condition I, Group A, and three subjects were dropped from Condition II, Group A when they failed to face the modeling stimulus.

There were no differences in activity level between groups $\left(\mathrm{x}^{2}=.89 ; \mathrm{df}=1 ; \mathrm{pH}_{\mathrm{o}} \mathrm{x}^{2} \geqslant \chi^{2} \geqslant .50\right)$.

Seventeen Group A subjects and 20 Group B subjects died. No significant difference was found in death rates with a $\mathrm{x}^{2}$ analysis $\left(\mathrm{x}^{2}=.277, \mathrm{df}=1\right.$; $\mathrm{pH}_{\mathrm{o}} \mathrm{x}^{2} \geqslant \chi^{2} \geqslant .70$ ).

As shown in Figure 1, the median response latency for chicks observing an imprinted model was 2 min and $26 \mathrm{sec}$. The median response latency for chicks which observed a nonimprinted model was 3 min. The median response latency for control chicks was $10 \mathrm{~min}$. The median response latency for the entire sample was $5 \mathrm{~min}$ and $39 \mathrm{sec}$.

There was a significant effec: for exposure to modeling compared to control groups $\left(x^{2}=19.14\right.$; $\left.\mathrm{df}=2, \mathrm{pH}_{\mathrm{o}} \mathrm{x}^{2} \geqslant \chi^{2} \geqslant .001\right)$.

As shown in Table 1, Group B chicks had significantly shorter latencies in the experimental conditions than Group A chicks $\quad\left(x^{2}=13.44 ; \quad d f=1\right.$; $\left.\mathrm{pH}_{\mathrm{o}} \mathrm{x}^{2} \geqslant \chi^{2} \geqslant .001\right)$.

\section{DISCUSSION}

There were no differences between the two groups' death rate and activity level. This supports the pilot study findings that when chicks are individually housed and provided with a social surrogate, they are not functionally social isolates. This use of social surrogates in chicks warrants further investigation.

An observational learning effect was clearly demonstrated by the delayed reproduction of a novel response in chicks exposed to both imprinted and nonimprinted modeling stimuli. This meets Band ıra's (1971) criteria for observational learning involving a symbolic process. The median score of $10 \mathrm{~min}$ (failure) for the control group supports the previous research findings that solution of the umweg problem is a novel response in chicks.

No differences were found between problem solving in chicks exposed to an imprinted modeling stimulus as opposed to a nonimprinted modeling stimulus. This suggests that imprinting on the model neither interfered with nor facilitated the chick's gathering of information about his environment. Hence, in this study, the model functioned mainly as a discriminative stimulus. It is particularly interesting that Group A chicks raised with other chicks should learn any thing at all from a red tennis ball. A possible explanation for the apparently equivalent discriminative value of the two stimuli could be that novel stimuli and stimuli with positive social value are equally effective in enhancing the stimulus value of the model for chicks.

Chicks imprinted on the red tennis balls had significantly shorter latencies than chicks imprinted on other chicks. It is suggested that the similarity of the small individual cages to the small observational cells required less adaptation for the individually housed chicks than for the chicks housed in a brooder. The group raised chicks had, in effect, both a novel cage and a novel problem situation to adapt to while the individually raised chicks were exposed to the novel problem without this distraction.

Table 1

Extension of the Median Test Comparing Differences in Response Latency for Group A and Group B in Experimental Conditions

\begin{tabular}{lcc}
\hline $\begin{array}{c}\text { Scores } \\
\mathrm{md}=2^{\prime} 37^{\prime \prime}\end{array}$ & $\begin{array}{c}\text { Group A } \\
\text { Condition I/II } \\
\mathrm{N}=20\end{array}$ & $\begin{array}{c}\text { Group B } \\
\text { Condition I/II } \\
\mathrm{N}=24\end{array}$ \\
\hline $\begin{array}{l}\text { Above the } \\
\text { Median } \\
\begin{array}{l}\text { At or Below } \\
\text { the Median }\end{array}\end{array}$ & 16 Plus & 5 Plus \\
\hline
\end{tabular}




\section{REFERENCES}

Bandura, A. Psychological modeling, conflicting theories. New York: Adline-Atherton, 1971.

Bateson, R., \& Reese, E. P. Imprinting (film). Cambridge: Appleton-Century-Crofts, 1968.

Hess, E. H. "Imprinting" in animals. Scientific American, March 1958. Pp. 13-17.

Munn, N. L. The evolution of mind. Scientific American. 1957, $196,144$.
Resevez, G. System der optishen und haptishen Raumtauschungen. Zeitschuft fur Psychologie, 1934, 131, 296-375.

Siegel, S. Nonparametric statistics for the behavioral sciences. New York: McGraw-Hill, 1956.

Thorndike, E. L. Animal intelligence. Psychological Review Monograph, 1898, 2, 35-55.

(Received for publication March 17, 1975.) 